\title{
O conceito de atrito estático e a abordagem experimental para estudantes de Ensino Médio
}

\author{
Ferreira, M. V. V. ${ }^{1}$ \\ 1 Universidade Federal do Espírito Santo, Vitória, ES, Brasil
}

\begin{abstract}
Resumo
O objetivo deste artigo é demonstrar que através do método experimental é possível obter maior compreensão por parte dos alunos sobre o conceito de atrito estático, bem como na determinação do coeficiente de atrito. Através do paradigma da Física Experimental, que tem por objetivo introduzir o estudante em técnicas de obtenção de resultados é possível aplicar os conceitos teóricos de forma prática e dinâmica. A pesquisa foi realizada em uma escola do interior, economia predominantemente rural. Para obtenção dos dados para pesquisa foram aplicados três questionários e duas aulas, sendo que o primeiro questionário foi aplicado sem explicação alguma para obter o nível de conhecimento de cada aluno sobre o assunto e o segundo questionário após uma aula teórica e o terceiro após a aula experimental. $O$ resultado mostra que através do método de ensino experimental os alunos apresentam melhor aproveitamento nos conteúdos de física, os alunos mostraram um incremento no índice de acerto de $28 \%$ devido à aula experimental.
\end{abstract}

Palavras chaves: Ensino de física, coeficiente, experimental.

\section{Introdução}

Desde os tempos pré-históricos foi descoberto que atritar duas pedras por determinado tempo era possível produzir fagulhas incandescentes que possibilitou 0 homem a controlar o fogo [1]. Além disso, a civilização egípcia utilizou-se do conceito sobre forças de atrito, para construção das pirâmides tal que as rochas eram transportadas de um lugar para outro e era utilizado gordura de vegetais para diminuir o atrito [2].

De fato o conceito de atrito é um tema atual e é usado para diversas tarefas como, por exemplo, lixamento de parede para posterior pintura, adequação de pavimento de estradas e aeroportos, usinagem de peças metálicas [2].

Mesmo o conceito presente no dia a dia, alunos de ensino fundamental e médio demonstram dificuldades para assimilar este conteúdo nas aulas da disciplina de ciências ou física. Um exemplo é o resultado do Exame Nacional do Ensino Médio onde uma análise qualitativa das questões de físicas tem índice de acerto não satisfatório [3].

Para contornar esta dificuldade inerente ao processo de ensino-aprendizagem, Viera e colaboradores [4] propuseram utilização de experimentos em sala de aula como uma ferramenta eficaz para dirimir as deficiências de aprendizagem. Neste contexto, este trabalho propõe aplicar aulas experimentais em paralelo à exposição de conteúdo teórico para que os conceitos de física sejam assimilados pelos estudos do ensino básico. A proposta aqui leva em consideração o paradigma de baixo custo [5,6]. O objetivo do artigo é demonstrar que através do método experimental é possível obter maior compreensão por parte dos alunos sobre os conceitos básicos da física $[7,8]$.

Para este estudo, foi escolhida a unidade de ensino de 1 e e $2^{\circ}$ grau de Ponto Alto, localizada no distrito de Paraju, Domingos Martins, ES. O número de alunos que participaram da pesquisa foi no total de 15 (quinze) alunos. É importante salientar que a economia local predominante é agropecuária [9].

\section{Metodologia}

Para avaliar o conhecimento prévio do grupo de alunos foi aplicado um questionário (Q1) de múltipla escolha cujas perguntas eram sobre o conceito de atrito. Nesta etapa o professor não fez nenhuma explicação sobre o assunto. 


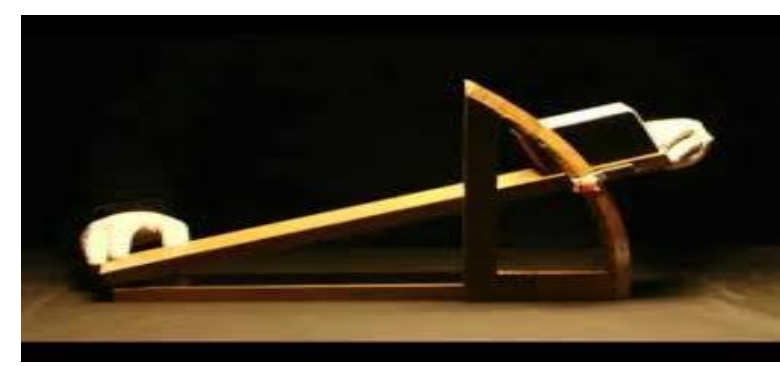

Figura1: Experimento de determinação do coeficiente de atrito estático.

Em seguida o professor fez uma explicação usando somente o método tradicional de ensino, ou seja, houve uma explanação do conceito de atrito sem qualquer recurso experimental. Após a aula foi aplicado um questionário (Q2) com perguntas similares ao questionário Q1. Por fim, o professor realizou um experimento para demonstrar o coeficiente de atrito estático. A experiência está representada na Figura 1 que consiste de um plano inclinado com ângulo regulável e um bloco de madeira. Após a aula, foi aplicado um terceiro questionário sobre o assunto (Q3).

As respostas dos questionários foram avaliadas quanto aos acertos e erros. Os resultados estão dispostos na Figura 2. Observou-se que no primeiro questionário o índice de acerto foi de $67 \%$ e que após a aula sobre o conceito de atrito o número de acerto aumentou. Além disso, pode-se notar que após a aula experimental o índice de acerto foi $95 \%$. O gráfico ajuda visualizar esta evolução na fixação do conceito de atrito pelo grupo de alunos.

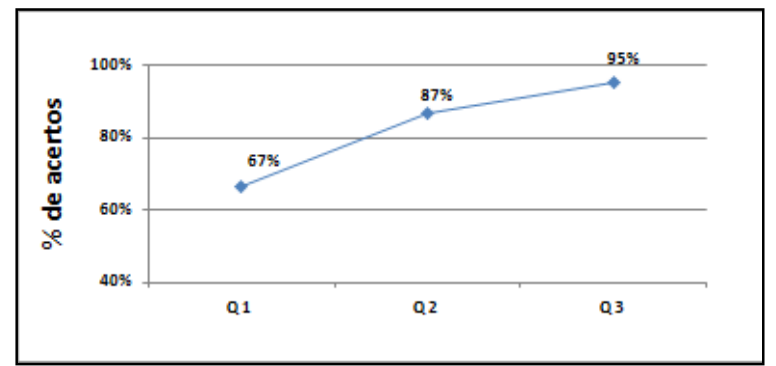

Figura 2: Média dos alunos do primeiro, segundo e terceiro ano nos questionários: formula de calculo (Somatório das notas de cada turma nos três questionários)/(nํำ de turma).

\section{Conclusão}

Neste trabalho, apresentou-se uma proposta de Ensino de Física através do experimento, onde foi trabalhado como determinar um coeficiente de atrito estático em um plano inclinado a um grupo de alunos do Ensino Médio.

Os alunos demonstraram que através da atividade prática desenvolvida é possível obter melhor compreensão dos conceitos físicos. Outro ponto a ser destacado foi à dificuldade inicial dos alunos em responder o primeiro questionário sem explicação sobre 0 assunto.

O segundo questionário após a aula teórica apresentou um aumento significativo no número de acerto, já o resultado obtido no terceiro questionário após a aula experimental foi satisfatório e indica que o instrumento de aprendizagem da física experimental possui melhor fixação de conceitos e produz um processo de ensino prático de qualidade, e nessa perspectiva entendemos a experimentação como parte integrante e fundamental do processo de ensino-aprendizagem de física.

\section{Referências}

[1] MENDONÇA, Lucas. Experimentos de Força de atrito- Dissertação (Ensino de Física) - UFSCAR, 2010.

[2] RAMALHO Francisco; Nicolau; Toledo. Os fundamentos da Física I, Editora Moderna, 1999.

[3] GONÇALVES Wanderley P. e BARROSO, Marta F.; Revista Brasileira de Ensino de Física, v. 36, n. 1, 1402 (2014).

[4] VIEIRA, L.P.; AMARAL, D.F.; LARA, V.O.M.; Revista Brasileira de Ensino de Física, v. 36, n. 1, 1504 (2014).

[5] BORGES, A.T. Caderno Brasileiro de Ensino de Física 19, capa n.3 (2002).

[6] PASSOS, Carlos Augusto C.; Orlando, Marcos Tadeu D, Pesquisa e prática pedagógica laboratório ensino física 3, UFES, Ne@ad, 2012.

[7] UFMG, Introdução a física experimental, 2014. Disponível em:<http://www.fisica.ufmg.br/ lab1/>. Acesso em 23 de abril de 2014.

[8] PACHECO, D. A experimentação e o ensino de ciências. Ciência \& Ensino. V. 2, 1997.

[9] INCAPER, Programa de assistência técnica e extensão rural, 2011/2013. Disponível em:<http://www.incaper.es.gov.br/proater>. Acesso em 22 de abril de 2014 